\title{
An experimental evaluation of toxic gas emissions from vehicle fires
}

\author{
Benjamin TRUCHOT ${ }^{1}$, Fabien FOUILLEN ${ }^{1}$, S. COLLET ${ }^{1}$ \\ ${ }^{1}$ INERIS, Parc technologique ALATA, France
}

\begin{abstract}
Improving fire modelling is a key issue to design efficient safety measures for a safe people evacuation in case of fire. Such an analysis should consider the different impacts of fire on people as temperature, visibility but also toxicity. Most of the standard curves used in tunnel fire studies are based on quite old fire tests without any detailed toxic gas qualification. Very few fire tests were published in that way. Based on those few tests, some standard fire emission factors are available in the literature. The objective of this paper is to review those emission factors considering the different toxic species and dealing with using recent cars. A method is then proposed to define a carbon monoxide equivalent emission factor to consider the different species through their specific threshold. Such an approach can be easily introduced into fire codes.

To meet this objective, two series of tests were performed. The first concerns individual combustible materials of cars as plastics and tyres. The second focusses on full car burning tests including a detailed smoke analysis. Those two series of tests lead to an analysis of the smoke toxicity and a comparison of emission factors with standard ones.
\end{abstract}

KEYWORD: smoke toxicity, car burning tests

\section{INTRODUCTION}

In case of fire in underground facilities such as tunnels or car parks, while heat release rate (HRR) is crucial for structure behaviour and aerodynamic, impact on people is mainly governed by the smoke toxicity. However, while car fires were largely studied in the past regarding the HRR, few papers were focussed on the toxic gas emissions [1][2]. Since those papers were published, cars were concerned by major improvements as new systems for comfort, that have induced, as far as the topic of this paper is concerned, a major increase of the mass of plastic, or new energy carriers. Each of these improvements could clearly impact the toxic gases emission factors in case of fire.

To evaluate recent cars emission factors, a large scale experimental fire campaign with real cars were performed. Those tests concern several categories of cars. The first is a series of three different recent cars, with several sizes, from small "urban" cars, as Renault Twingo, Citröen C1 or Fiat Panda, to large "familial" cars, as Citroën C5, Volkswagen Passat or Peugeot 508. This first series of tests, compared with existing results in the literature, enables evaluating the impact of embedded comfort system on smoke toxicity. The second series of tests concerns the evolution of the energy carrier using the results from electric cars burning [3]. Tests were also achieved on different materials individually such as fuels, cables and plastics to provide a more detailed analysis. Because carbon monoxide is not the only toxic product that is generated in case of fire, emissions were, during those tests, characterized using a FTIR (Fourier Transform Infra-Red) spectrometer. Such a system enables performing a detailed measurement including the concentration of carbon monoxide, but also of acid gases (hydrogen chloride, hydrogen fluoride, ...) or other products as formaldehyde for example. Not only the nature but also the quantity of produced gases during fire are compared.

Regarding those experimental data, made on recent cars in a tunnel like environment, a comparison is proposed with the commonly used fire curves [4] for the emission factor. To let this comparison possible, a CO equivalent source term is defined based on both a simple approach [5], the ISO toxic evaluation standard method [6][7] is also used for toxic consequences evaluation. 


\section{VEHICLE FIRE SOURCE TERMS AVAILABLE}

Considering that most of the toxic gas emission factors from fires are given relatively to the heat release rate (HRR), it appears important to first consider this quantity. Furthermore, the smoke behaviour in a confined or semi-confined infrastructure will highly depends on the thermal gradient that governs smoke stratification.

Regarding HRR, several curves of HRR vs time are available in the literature. Those curves were obtained using different measurement methods that could be calorimetry installation [3][8], tunnel fire tests [9] or external measurement [10]. French nationally recognised document [4] or AIPCR publication [11] also give an overview of available data. The published curves of HRR are based on different values of the total amount of energy released during the fire, i.e. the HRR curve integral. The released energy then varies from $3000 \mathrm{MJ}$ [4] to $12000 \mathrm{MJ}$ [8]. To provide an example, two HRR curves are plotted hereafter on Figure 1. The first from [4], on the left part of the figure, is the standard curve commonly used for fire safety studies in France. It is based on a synthesis of available data. The second, from [11], on the right part of the figure, is an example of measured HRR curve during the Eureka campaign [9] for an individual car containing plastics.
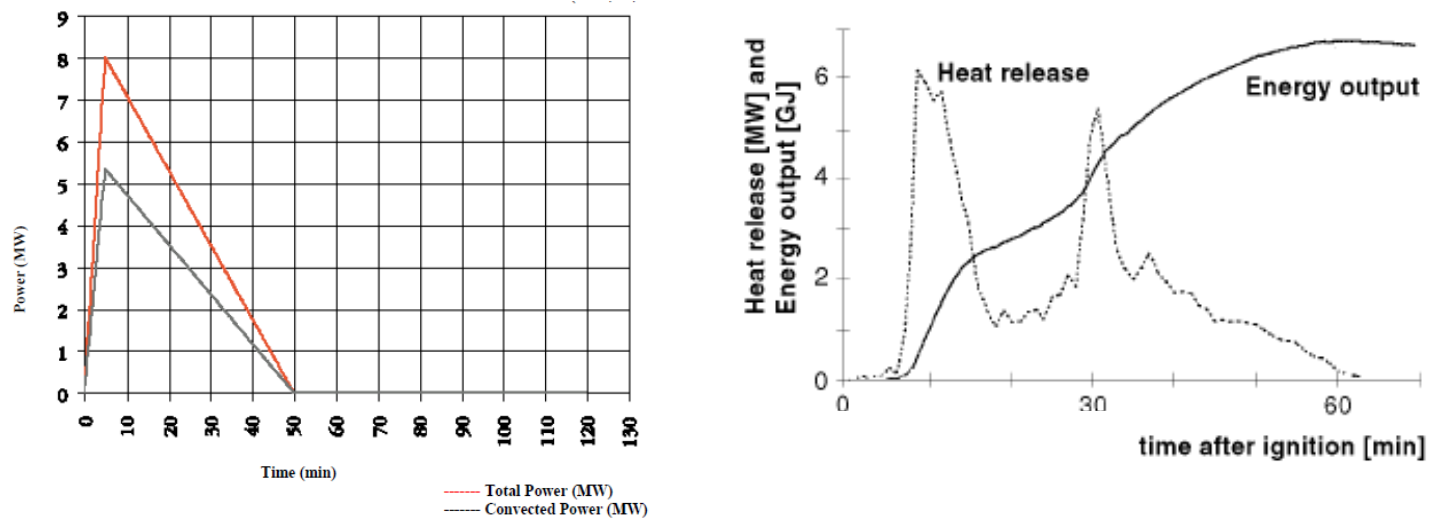

Figure 1: Two examples of HRR curves from French ce documentation, 12000 MJ [4] (left) and form PIARC reference, $7000 \mathrm{MJ}$ [11](right).

It must be highlighted that the range of values is quite important, not only in terms of HRR peak value, from 2.5 to more than $8 \mathrm{MW}$ depending of the nature of the car [8], but also regarding the fire kinetic with a peak value reached between 5 [4] and more than 40 min depending on fire test conditions [10]. The important issue regarding toxicity is then the relation between the HRR and the emission factor. This relation is governed by the characteristics of combustible materials that are not so different between small and large cars. While some data are available in the literature regarding the emission rate of carbon dioxide and carbon monoxide, few data exists on the other toxic gases that can be produced during a car fire. One of the most detailed is [2]. Those tests, achieved in 1999, deal with vehicles that are quite old now.

It is then interesting to evaluate the impact of vehicle improvements between previous and current tests in terms of chemical species generated by the fire but also in terms of emission factor.

\section{TESTS ON INDIVIDUAL ELEMENTS}

Before going any further in the description of full scale fire tests on vehicles, it is important to analyse emission factors for different individual materials. This topic was previously addressed in the literature $[12][13][14][15]$. It is important to note that results presented in this paper are focussed only on chemical species that could induce acute toxicity.

\section{Brief description of experimental facilities}

This series of tests was achieved in the INERIS $80 \mathrm{~m}^{3}$ room, a $5 \mathrm{~m}$ long, $4 \mathrm{~m}$ width and $4 \mathrm{~m}$ height concrete building. Ventilation in this room is made through a $1 \mathrm{~m}^{2}$ extraction duct located in the center of the roof. Air inlet is also a $1 \mathrm{~m}^{2}$ opening in one of the walls, it is located just above the ground. The 
ventilation flow rate was set to $10000 \mathrm{~m}^{3} / \mathrm{h}$, this flow rate was chosen to prevent any under ventilation effect on the fire.

During those tests, combustible samples were placed in the center of the room, in a metallic cylindrical container placed over a sand insulation layer. Ignition was achieved with an $80 \mathrm{~kW}$ propane burner applied during 1 minute. To ensure long duration tests, fires were refueled during the measurement period.

\section{Main results}

During this experimental campaign, four combustible materials from real cars were burnt individually: gasoil, plastics, tyres and cables. Those elements were taken from commercial cars to be representative of real materials. Plastics and tyres were previously crushed. Main results are summarized in Table 1. Of course, many other chemicals were measured but not all can be detailled in the present paper, more details can be found in [16]. It was chosen here to focus on the most relevant products regarding acute toxicity. For each material, the total duration of the tests was longer than 3 hours.

Table 1: Synthesis of individual combustible material fire tests.

\begin{tabular}{|c|c|c|c|c|}
\hline $\begin{array}{c}\text { Mass of product } \\
\text { burn [kg] }\end{array}$ & Gasoil & Plastics & Tyres & Electric cables \\
\hline \multicolumn{5}{|c|}{ Emission factors [mg/g] or [g/kg] } \\
\hline $\mathrm{CO}_{2}$ & 2823 & 2034 & 49 & 769 \\
\hline $\mathrm{CO}$ & 31 & 20 & 42 & 9.1 \\
\hline $\mathrm{HCl}$ & - & 2.2 & 0.2 & 2.1 \\
\hline $\mathrm{HF}$ & - & 0.014 & 0.003 & 0.11 \\
\hline $\mathrm{NOx}$ & 1.2 & 5,0 & 2.8 & 2.5 \\
\hline $\mathrm{SO}_{2}$ & 0.1 & - & 10 & - \\
\hline
\end{tabular}

Considering that the main toxicity contribution is not necessarily for the larger produced quantity because of the important ratio of toxic thresholds, those emission factor values should be considered carefully. This can be illustrated through the non-reversible toxic threshold for $60 \mathrm{~min}$ exposure that is $40 \mathrm{ppm}$ for $\mathrm{HCl}$ against $800 \mathrm{ppm}$ for $\mathrm{CO}$, this means that producing 20 times less $\mathrm{HCl}$ than $\mathrm{CO}$ will lead to similar consequences, i.e. potential non-reversible impact on human beings. Those preliminary tests clearly indicate that all toxic gases emissions should be considered for evaluating the toxic impact of a fire and not only $\mathrm{CO}$. This table also shows that some materials are responsible of some specific emissions such as tyres for $\mathrm{SO}_{2}$ or plastics and cables for $\mathrm{HCl}$.

\section{FULL SCALE CAR BURNING}

\section{Brief description of experimental facilities}

Full scale fire tests were achieved in the INERIS fire gallery. This fire gallery was described in some previous papers [17] but relevant details are given hereafter. This gallery, made with concrete, is $50 \mathrm{~m}$ long with a $3 \mathrm{~m}$ width and $3.3 \mathrm{~m}$ maximum height section. It is equipped with fans that can be controlled to manage the air flow in the tunnel. Photography of INERIS fire facilities is presented on Figure 2. 


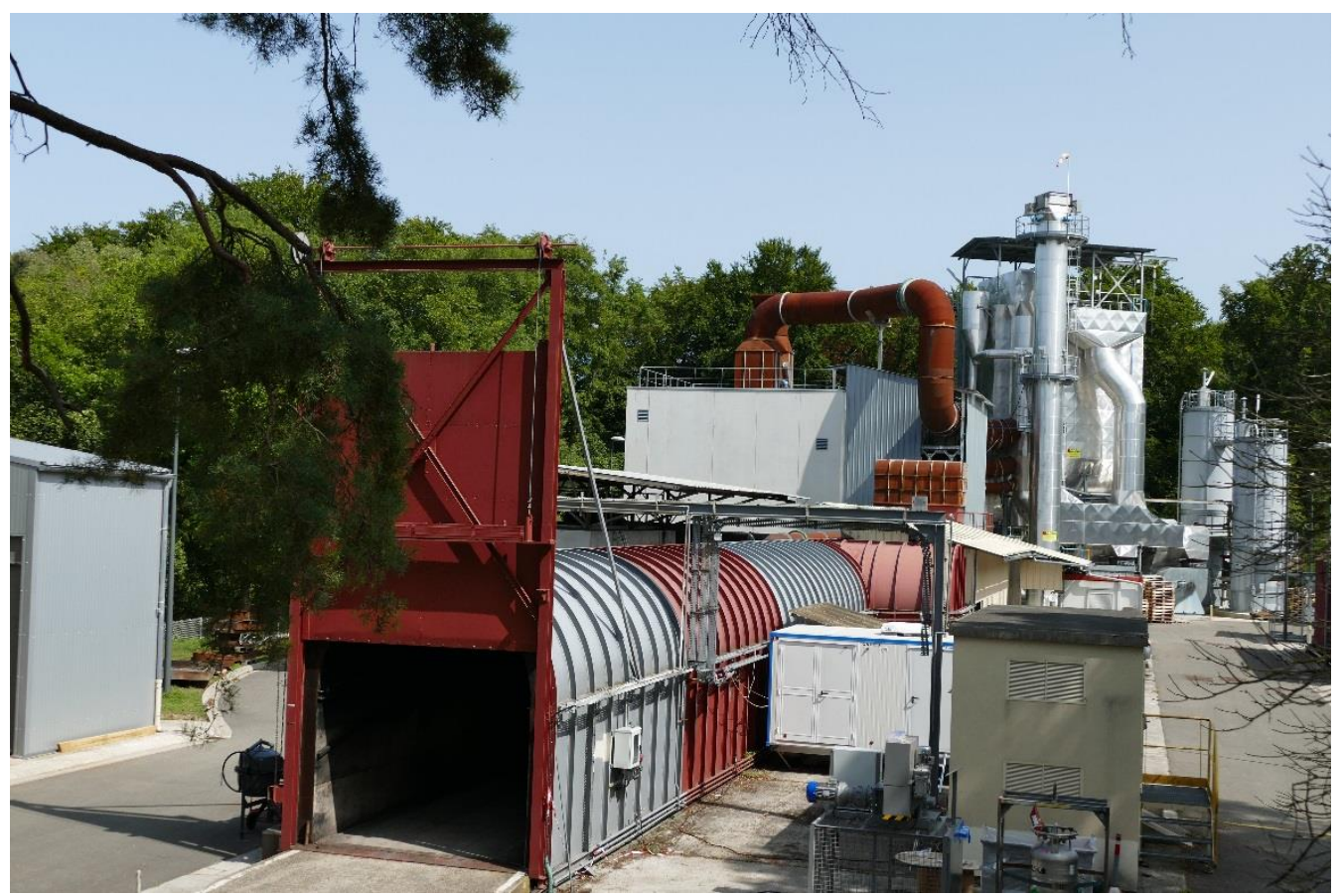

Figure 2 : INERIS fire gallery.

One of the main features of this installation consists in the smoke treatment system installed downstream. This system, of a similar design as a garbage furnace, enables capturing not only the accute toxic products as carbon oxides or acid gases but also chronical toxic species, as dioxin or PAH (Polycyclic Aromatic Hydrocarbons) too [18].

\section{Experimental setup}

Measurements made during the tests are located on the scheme reproduced on Figure 3. Because of their importance, carbon oxides and oxygen measurements were made on several points. The interest was not only to ensure the availability of the measurement but also to demonstrate that the smoke is perfectly mixed in the air flow on measurement points. Combustion products were measured with both an online method, based on a FTIR spectrometer for acid gases and carbon oxides, coupled with a NDIR (Non-Dispersive InfraRed) analyzer for $\mathrm{CO}$ and $\mathrm{CO}_{2}$, and a FID (Flame ionization detector) analyzer for hydrocarbons, and with integral method using bubblers. Oxygen consumption was measured with a paramagnetic analyzer. 


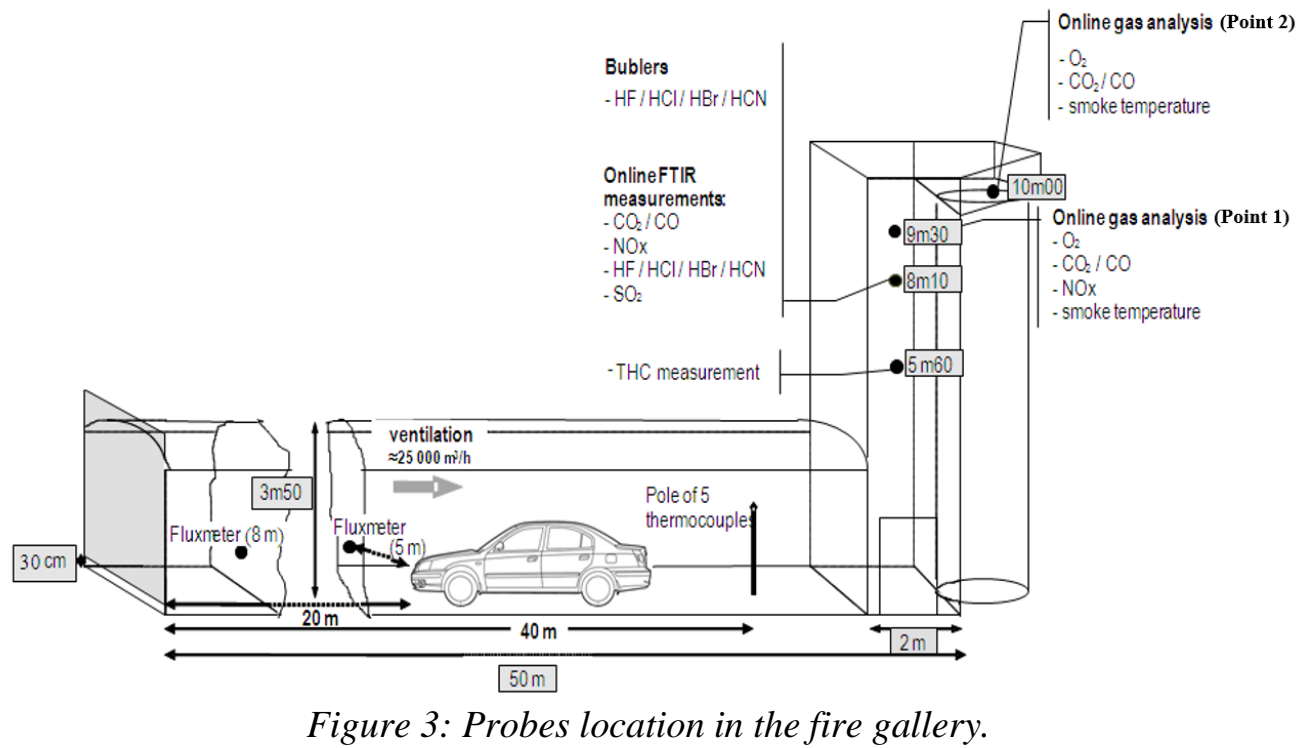

Ventilation flow rate was set to $25000 \mathrm{Nm}^{3} / \mathrm{h}$ (about $7 \mathrm{~m}^{3} / \mathrm{s}$ ) for those tests. Such a flow rate induced a velocity just under $1 \mathrm{~m} / \mathrm{s}$ in the gallery. Considering that the expected HRR for such fire is around $8 \mathrm{MW}$, the required minimum air flow to prevent under ventilation effect is $4.8 \mathrm{~m}^{3} / \mathrm{s}$, this value enables ensuring that the consumption $\mathrm{O}_{2}$ will not exceed $45 \%$ of the available mass of $\mathrm{O}_{2}$. This means that, in the present configuration, air flow is large enough to prevent from oxygen controlled fire.

\section{Brief description of cars and calorimetric data}

During this experimental campaign, two series of cars were used. The ignition process was different for those tests. For cars 1, 2 and 4, ignition was made inside the vehicle by igniting the front left seat using a $20 \mathrm{~kW}$ propane burner. For car 3, ignition was achieved by a $0.25 \mathrm{~m}^{2}$ heptane pool fire located under cover, near the front right wheel. First results for those cars are presented in Table 2. On top of car characteristics, this table provides some basic calorimetric data measured during tests as HRR peak value and the total released energy, obtained by the HRR curve integration. It is important to note that some measurements can be influenced by the experimental facility characteristics. Then, while the total amount of energy, or the total amount of toxic gases are probably not significantly influenced, the HRR peak value is probably overestimated compared to a free burning because of the confinement.

Table 2: Main characteristics of burnt cars.

\begin{tabular}{|c|c|c|c|c|}
\hline $\begin{array}{c}\text { Total mass before } \\
\text { ignition [kg] }\end{array}$ & Car 1 & Car 2 & Car 3 & Car 4 \\
\hline Energy carrier & Fuel & 1404 & 1564 & 1501 \\
\hline Category & Urban car & $\begin{array}{c}\text { Medium class } \\
\text { familial car }\end{array}$ & $\begin{array}{c}\text { Upper class } \\
\text { familial car }\end{array}$ & $\begin{array}{c}\text { Medium class } \\
\text { familial car }\end{array}$ \\
\hline $\begin{array}{c}\text { Total mass loss } \\
{[\mathrm{kg}]}\end{array}$ & 192 & 275 & 262 & 278.5 \\
\hline $\begin{array}{c}\text { Mass loss fraction } \\
{[\%]}\end{array}$ & 17 & 19.6 & 16.8 & 18.6 \\
\hline Peak HRR [kW] & 4900 & 5900 & 7800 & 4500 \\
\hline $\begin{array}{c}\text { Time between } \\
\text { ignition and peak } \\
\text { HRR [min] }\end{array}$ & 15 & 18 & 15 & 30 \\
\hline $\begin{array}{c}\text { Total released } \\
\text { energy [MJ] }\end{array}$ & 6890 & 10600 & 10000 & 8540 \\
\hline
\end{tabular}

Those values were compared with onesome available data as those defined in the AIPCR reference 
document [7], the CETU French guide [4] or some published data, summarized in Table 3.

Table 3: Calorimetric values from different publications.

\begin{tabular}{|c|c|c|c|}
\hline & Peak HRR [kW] & $\begin{array}{c}\text { Time between } \\
\text { ignition and } \\
\text { HRR peak [min] }\end{array}$ & $\begin{array}{c}\text { Total released } \\
\text { energy [MJ] }\end{array}$ \\
\hline AIPCR guide [7], urban car & 2500 & - & 6000 \\
\hline AIPCR guide [7], familial car & 5000 & - & 7000 \\
\hline CETU document [4], urban car & 4000 & 5 & 6000 \\
\hline CETU document [4], familial car & 8000 & 5 & 12000 \\
\hline Familial car [9] & 7000 & 7 & 9000 \\
\hline Electric urban car [11] & 6300 & 40 & 6400 \\
\hline
\end{tabular}

The first comparison shows that measured values are in quite good agreement with available data. The main difference appears in the delay to reach the peak HRR. Measured values are greater than the standard ones. It is important to remind the objectives of standards. Standard values are used for safety studies where minimizing the delay for fire propagation leads to minimize the available escape time for people and consequently improving safety level. In that sense, it could be considered as relevant.

\section{Gaseous emissions}

Before going into the comparison between vehicles, each toxic specie proportion in gaseous products are summarized on Table 4 for the three internal combustion engine (ICE) cars. Values given in this table are not the concentration of each gas but the ratio of the total produced mass of each gas to the total mass generated for all products listed in this table. To illustrate this, the maximum concentration of $\mathrm{CO}_{2}$ measured in the smoke and air flow mixture reaches about $40000 \mathrm{ppmv}$ (4 volume \%).

Table 4: Gaseous emissions data, ratio of produced mass to the total produced mass of those gases.

\begin{tabular}{|c|c|c|c|}
\hline & Car 1 & Car 2 & Car 3 \\
\hline $\begin{array}{l}\text { Relative emission [\% of } \\
\text { total] }\end{array}$ & & & \\
\hline \multicolumn{4}{|c|}{ Acid gases } \\
\hline $\begin{array}{c}\text { Hydrogen chloride } \\
(\mathrm{HCl})\end{array}$ & $0.38 \%$ & $0.29 \%$ & $0.33 \%$ \\
\hline Hydrogen fluoride (HF) & $0.12 \%$ & $0.11 \%$ & $0.07 \%$ \\
\hline $\begin{array}{c}\text { Hydrogen cyanide } \\
\text { (HCN) }\end{array}$ & $0.03 \%$ & $0.02 \%$ & $0.05 \%$ \\
\hline \multicolumn{4}{|c|}{ Carbon and nitrogen oxides } \\
\hline Carbon dioxide $\left(\mathrm{CO}_{2}\right)$ & $96.54 \%$ & $96.95 \%$ & $97.33 \%$ \\
\hline Carbon monoxide $(\mathrm{CO})$ & $2.29 \%$ & $2.11 \%$ & $1.94 \%$ \\
\hline Nitrogen oxide (NO) & $0.13 \%$ & $0.1 \%$ & \multirow{2}{*}{$0.15 \%$} \\
\hline Nitrogen dioxide $\left(\mathrm{NO}_{2}\right)$ & $0.06 \%$ & $0.06 \%$ & \\
\hline Sulfur dioxide $\left(\mathrm{SO}_{2}\right)$ & - & - & $0.13 \%$ \\
\hline \multicolumn{4}{|c|}{ Hydrocarbons } \\
\hline Total hydrocarbons & $0.45 \%$ & $0.37 \%$ & - \\
\hline
\end{tabular}

First, as for individual material tests, it must be noticed that the carbon dioxide proportion in smoke was higher than $95 \%$ for each test. This means that the total mass of $\mathrm{CO}_{2}$ produced by this fire represents about $95 \%$ of the mass produced for all the above-mentioned products.

One of the most important issue when dealing with smoke is the $\mathrm{CO} / \mathrm{CO}_{2}$ ratio that depends on external conditions and mainly the fire ventilation. In the present fire tests, the total ventilation air flow is about $25000 \mathrm{Nm}^{3} / \mathrm{h}$, i.e. $8.97 \mathrm{~kg} / \mathrm{s}$ of air and, consequently $2.06 \mathrm{~kg} / \mathrm{s}$ of oxygen. Considering $1 \mathrm{~kg}$ of oxygen is required to produce $13.1 \mathrm{MJ}$, it means that the air flow can generate a $27.0 \mathrm{MW}$ fire by consuming all provided oxygen. It can then be assumed that fires were sufficiently ventilated to prevent under ventilation phenomena. This should be demonstrated by the analysis of the $\mathrm{O}_{2}$ concentration and $\mathrm{CO} / \mathrm{CO}_{2}$ ratio evolution along the fire tests. Oxygen concentration downstream of the fire is plotted on 
Figure 4, concentration was measured at two distances downstream of the fire, about $30 \mathrm{~m}$ for point 1 and about $45 \mathrm{~m}$ for point 2 . The great accordance between values demonstrates the concentration homogeneity in smoke.

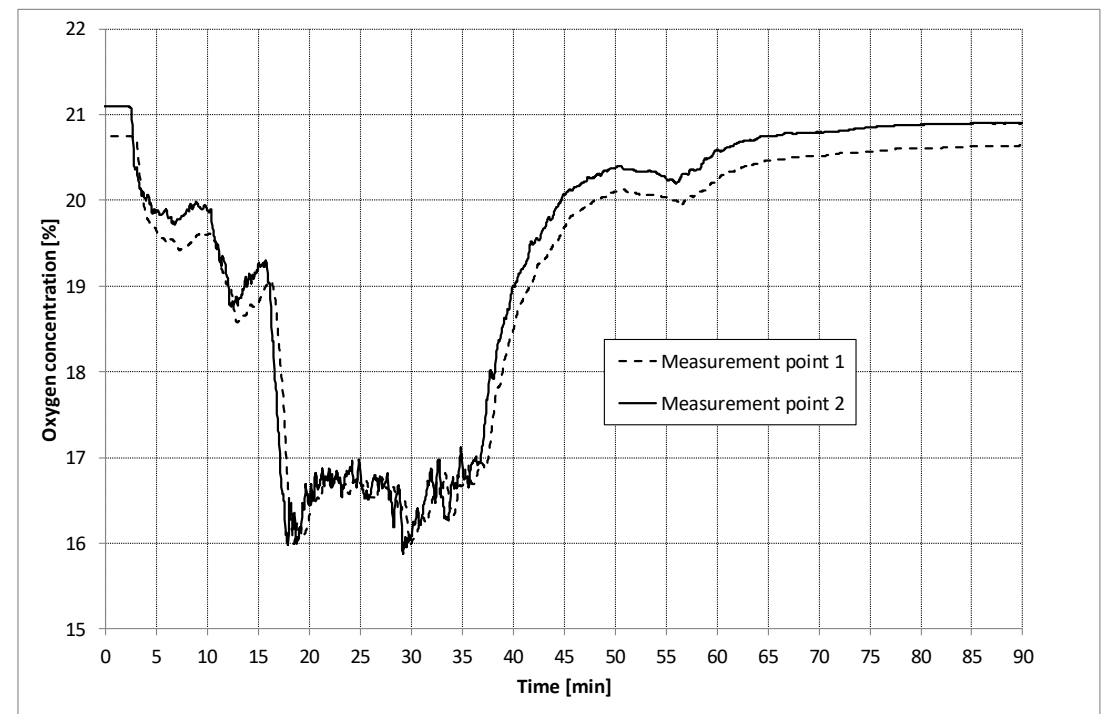

Figure 4: Evolution of oxygen concentration downstream the fire (car2).

This curve confirms that, when reaching the maximum HRR, the oxygen concentration is still above $16 \%$. The $\mathrm{CO} / \mathrm{CO}_{2}$ ratio is also time dependent, this is demonstrated on Figure 5.

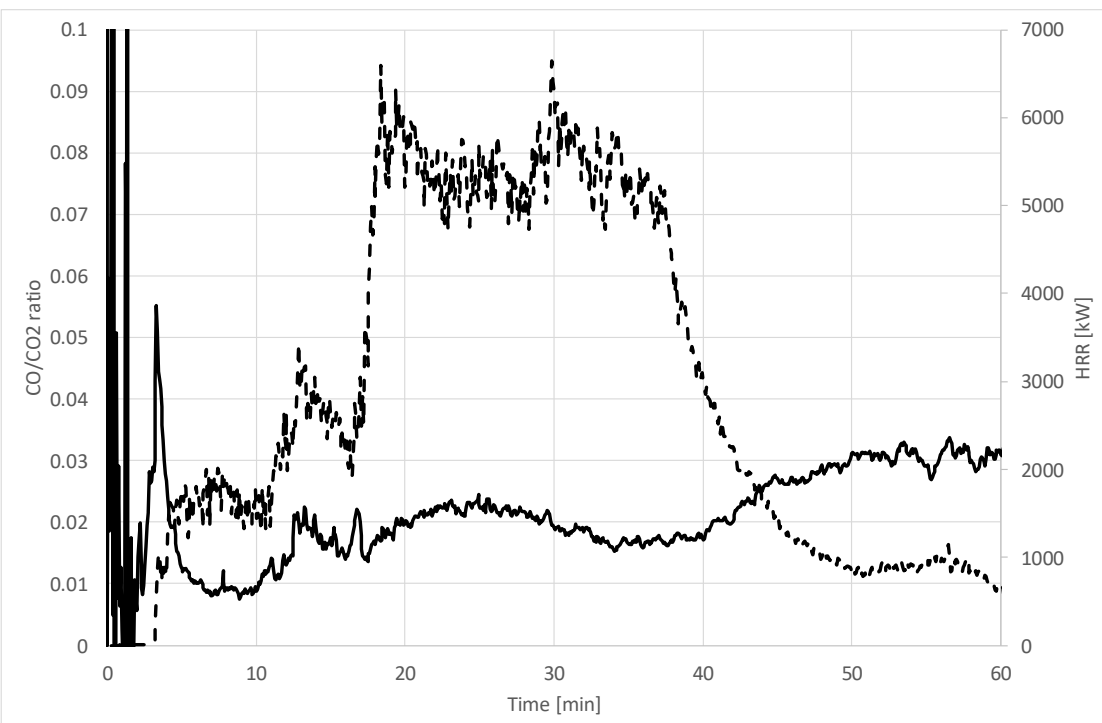

Figure 5: Evolution of $\mathrm{CO} / \mathrm{CO}_{2}$ ratio along time (continuous line) and $\mathrm{HRR}$ (dotted line) for car2.

This curve highlights that the $\mathrm{CO} / \mathrm{CO}_{2}$ remains quite constant during the whole fire duration, with a peak value under 0.05 . This value is in agreement with observations made by Tewarson at laboratory scale for different series of well-ventilated fires [21]. Identical conclusions were made for the other fire tests.

The other interesting point that should be discussed is the concentration of acid gases. For each car, the hydrogen chloride is the predominant acid gas in terms of total amount. However the evolution of acid gas concentration in smoke along during the tests reveals that the emission dynamic is specific to each gas with one main peak for HF emission, a continuous emission of $\mathrm{HCN}$ and several peaks for $\mathrm{HCl}$. An example is proposed on Figure 6 for car 3. 


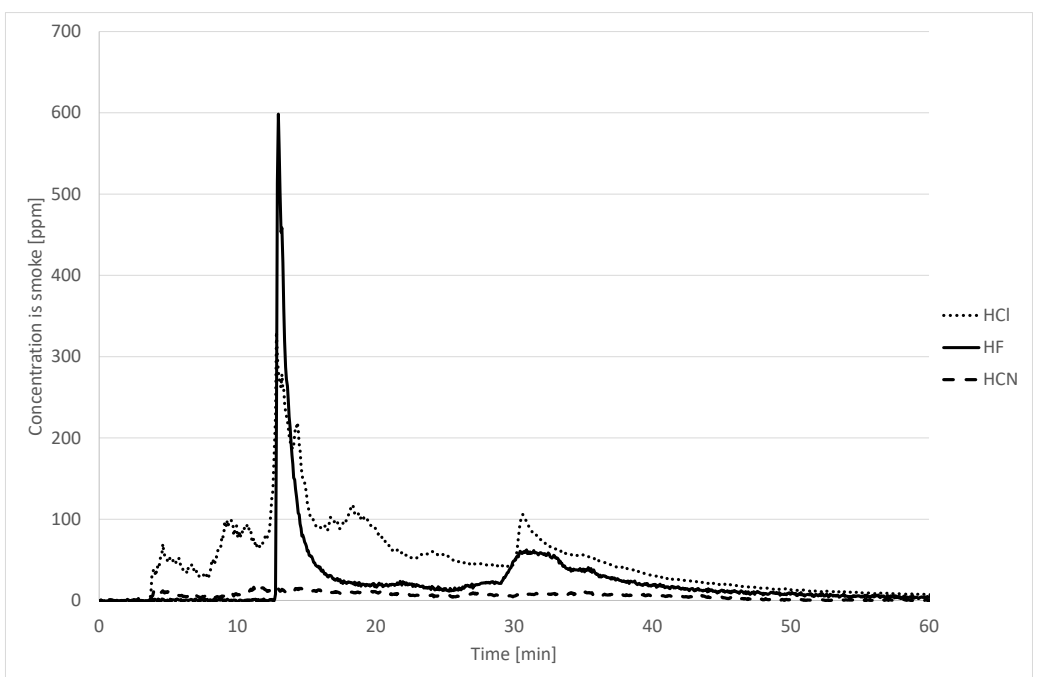

Figure 6: Acid gases concentration of acid gases in smoke versus time for car 3.

This curve shows that while hydrogen chloride is produced all along the fire, hydrogen fluoride is mainly generated during a short period. On top of that, regarding acid gases, the total amount of hydrogen cyanide is quite small, while seats contain a lot of foam. The evolution of gas production along time was identical for all the four cars burnt during this campaign.

It is then interesting to compare emissions for these acid gases with those available in the literature. The total amount of $\mathrm{HCN}$, resp. $\mathrm{HCl}$, measured during the tests presented in this paper is $0.15 \mathrm{~kg}$, resp. 1.8 $\mathrm{kg}$, while during tests managed by [2], that dealt with 90's car, the total amount of HCN was $0.17 \mathrm{~kg}$ and the one for $\mathrm{HCl}$ was $1.4 \mathrm{~kg}$. During those tests managed by [2], NOx were below the detection threshold while around $0.8 \mathrm{~kg}$ of NOx were measured during the campaign described in this paper. Regarding HF, concentrations were also below the detection threshold in [2], the total amount in the present tests was about $0.4 \mathrm{~kg}$.

\section{Impact of New Energy Carriers}

Because of the specific composition of batteries, electric cars are commonly supposed to produce more toxic gases in case of fire and mainly HF. Detailed data from electric cars bonfire were previously published [3]. Those tests were achieved in the same experimental facility as the one described in the present paper for car fire tests. Yet there are some specificities with these fires involving Li-Ion batteries.

First of all the heat release rate is found not to be modified by the battery. It was also shown that toxic gases production is similar between ICE cars and electric ones. The proportion of toxic species for electric cars are indicated in Table 5. As for Table 4 this does not correspond to the concentration of gases inside the smoke and ventilation air flow mixture but this is the ratio of the total amount of gas produced for each gas to the total mass of mentioned products. 
Table 5: Gaseous emissions data.

\begin{tabular}{|c|c|}
\hline & Car 4 \\
\hline Total amount of gas [g] & 737717 \\
\hline \multicolumn{2}{|c|}{ Acid gases } \\
\hline $\begin{array}{c}\text { Hydrogen chloride } \\
\text { (HCl) }\end{array}$ & $0.30 \%$ \\
\hline Hydrogen fluoride (HF) & $0.23 \%$ \\
\hline $\begin{array}{c}\text { Hydrogen cyanide } \\
\text { (HCN) }\end{array}$ & $0.02 \%$ \\
\hline \multicolumn{2}{|c|}{ Carbon and nitrogen oxides } \\
\hline Carbon dioxide $\left(\mathrm{CO}_{2}\right)$ & $96.98 \%$ \\
\hline Carbon monoxide $(\mathrm{CO})$ & $1.83 \%$ \\
\hline Nitrogen oxide $\left(\mathrm{NO}^{2}\right)$ & $0.12 \%$ \\
\hline Nitrogen dioxide $\left(\mathrm{NO}_{2}\right)$ & $0.05 \%$ \\
\hline Sulfur dioxide $\left(\mathrm{SO}_{2}\right)$ & - \\
\hline \multicolumn{2}{|c|}{$\mathrm{Hydrocarbons}$} \\
\hline Total hydrocarbons & $0.45 \%$ \\
\hline
\end{tabular}

This comparison clearly shows the peak values for emission factors are not significantly different. For the specific case of HF, the total amount about $0.7 \mathrm{~kg}$ for the electric car, is larger than the one for an identical ICE car, $0.4 \mathrm{~kg}$, but the peak emission factor is similar. This HF total amount is explained by the HF production from the battery that can be distinguished between 30 and 50 min on Figure 7. However, the emission curve of HF is, in the case of an electric car, not strongly different from an ICE car, with quite identical peak emission factor. As far as the total amount is concerned, other toxic gases are in the same range with for example, for the electric car, $1.6 \mathrm{~kg}$ of $\mathrm{HCl}$ and $0.15 \mathrm{~kg}$ of $\mathrm{HCN}$.

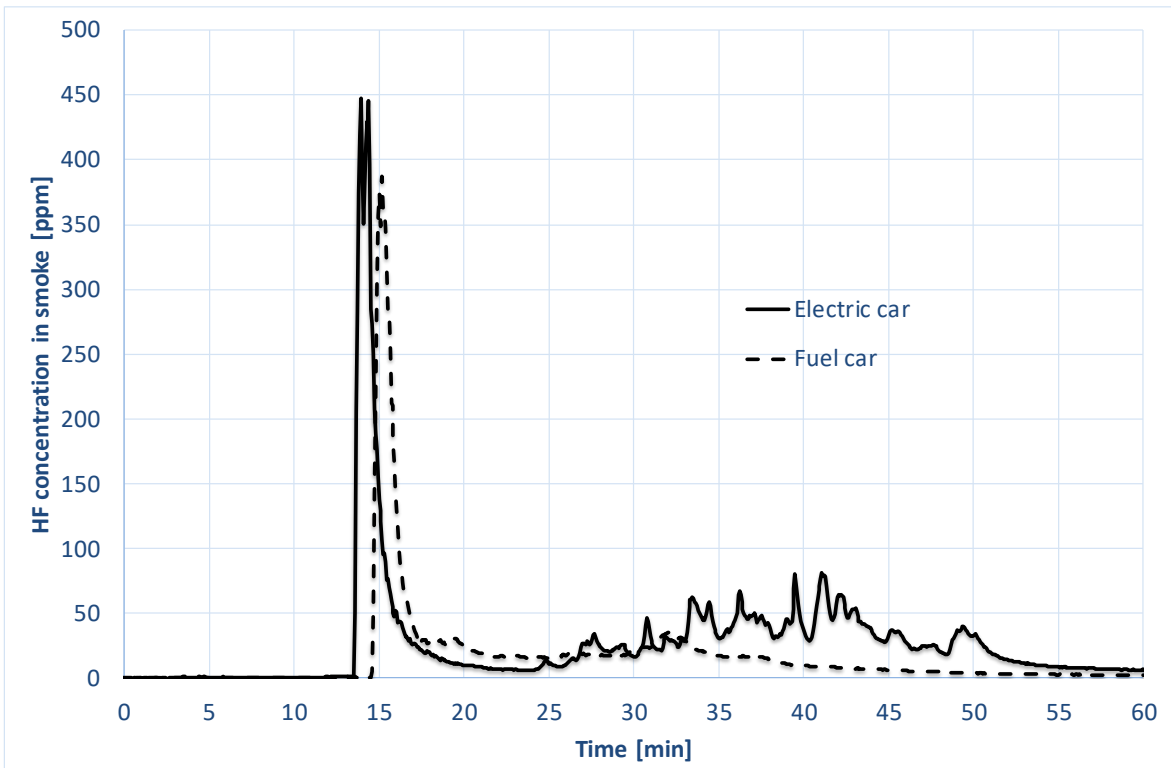

Figure 7: HF emission factor during the electric car (car 4) burning vs corresponding ICE car (car 2).

Of the way the vehicule is fueled, the first HF emission peak is identical, therefore, one may deduce that this gas comes from common part between ICE and electric vehicles such as fluorinated plastics or cooling system fluid.. The contribution of the battery appears during the second part of the fire, $30 \mathrm{~min}$ after ignition. In such a condition, this new energy carrier does not affect the smoke toxicity for people during evacuation that shall occur during the first minutes after ignition. 


\section{Equivalent toxicity}

Because smoke toxicity is a quite complex problem, mainly due to the requirement to take account vairous gases and their impact on human beings, a criterion should be defined to discuss about relative toxicity. Several methods exist in order to evaluate the impact of a toxic gases mixtures. The simplest approach considers an equivalent effect of each gas weighted by a given corresponding threshold [5]. Such an approach is also interesting here because it considers all gases without any distinction between asphyxiant and irritant effects. It consists in defining an equivalent threshold, $\mathrm{S}_{\mathrm{eq}}$ :

$$
\frac{1}{S_{e q}}=\sum_{i=1}^{n b_{-} t o x} \frac{\left[P_{i}\right]}{S_{i}}
$$

In this relation, $\left[\mathrm{P}_{\mathrm{i}}\right]$ represents the fraction of product $\mathrm{P}_{\mathrm{i}}$ in smoke and $\mathrm{S}_{\mathrm{i}}$ the corresponding toxic threshold for that gas, French non-reversible thresholds were chosen for this analysis but such an approach can also be achieved using AEGL-2 thresholds that represent the same kind of impact on human beings. Based on this relation, it is then possible to define an equivalent $\mathrm{CO}$ emission factor, each gas being considered having the same effect on human beings only corrected by its specific threshold. Each gas could then be introduced in the toxicity evaluation by multiplying the molar emission factor for the corresponding ratio.

As an example, considering the 10 min non-reversible thresholds for $\mathrm{CO}$ and $\mathrm{HCl}$, respectively $2600 \mathrm{ppm}$ and $240 \mathrm{ppm}$, the $\mathrm{CO}$ equivalent source term to represent $\mathrm{HCl}$ will be the $\mathrm{HCl}$ production rate multiplied by 2600/240. Corresponding thresholds for each gas, and the corresponding multiplication factors are then given in Table 6.

Table 6: 10 min non-reversible threshold and multiplication factor to determine CO equivalent source term.

\begin{tabular}{|c|c|c|}
\hline Gas & $\begin{array}{c}10 \text { min non-reversible } \\
\text { threshold }\end{array}$ & Multiplication factor \\
\hline $\mathrm{CO}$ & 2600 & 1.0 \\
\hline $\mathrm{HF}$ & 600 & 4.3 \\
\hline $\mathrm{HCl}$ & 240 & 10.8 \\
\hline $\mathrm{HCN}$ & 62 & 41.9 \\
\hline $\mathrm{NO}$ & 150 & 17.3 \\
\hline $\mathrm{NO}_{2}$ & 60 & 43.3 \\
\hline $\mathrm{SO}_{2}$ & 128 & 20.3 \\
\hline
\end{tabular}

Applying such a procedure for each toxic gas, enable building the equivalent $\mathrm{CO}$ emission factor for car fires. Of course, this factor cannot be constant and varies along time, as showed on Figure 8. 


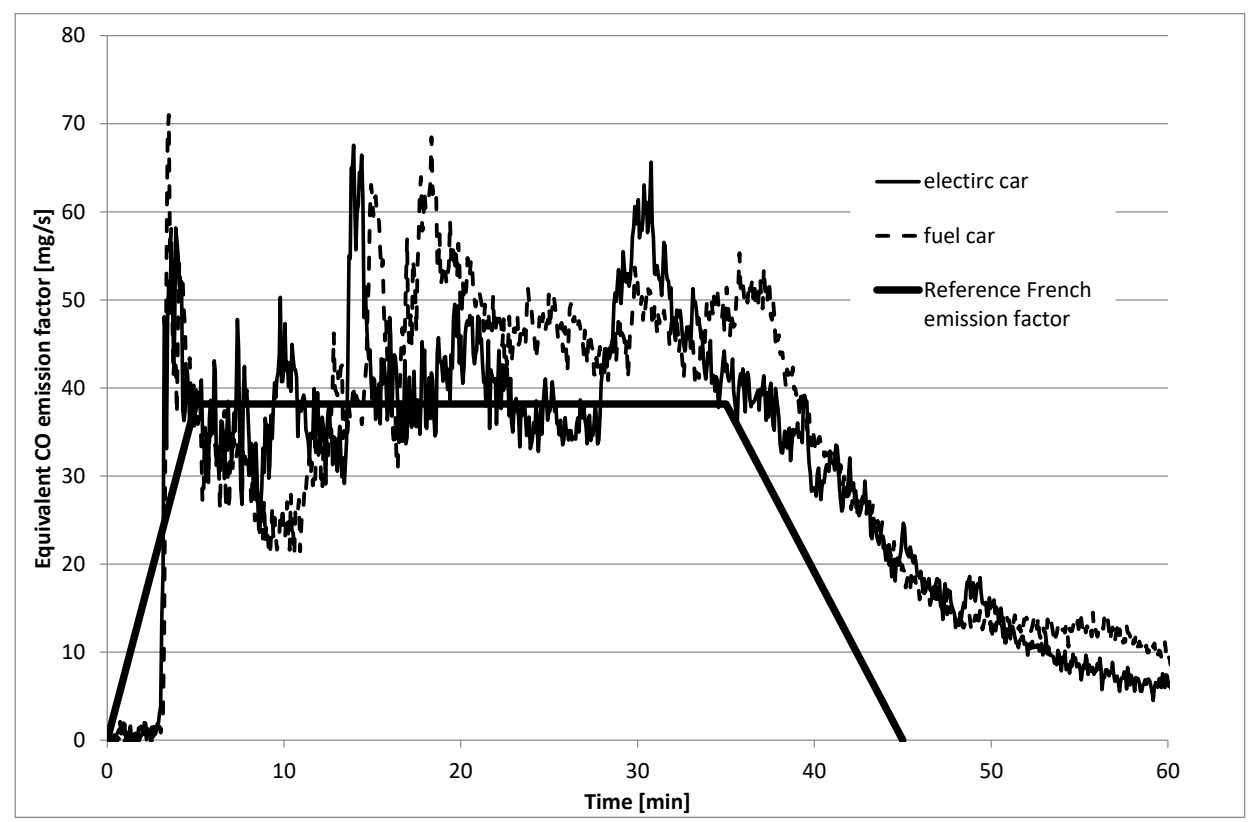

Figure 8: Evolution of CO equivalent emission rate along time, comparison of car 2 and 4, fuel and electric cars.

The emission factor evaluated for the tests described here can reach twice the referenced value used in French studies [4], that comes from a synthesis of available data when this document was published. On top of that, it shows that the maximum value can be reached during the first minutes of the fire. This period is crucial for people evacuation. This conclusion regarding emission factors has however to be considered with the conclusion regarding fire kinetic discussed previously. The measured fire growth during tests presented in this paper is slower than standard curves fire growth.

A more detailed approach for toxic emission evaluation is described in the ISO document 13571 [6]. This approach consists in defining the Fractional Effective Dose (FED) and Fractional Effective Concentration (FEC). It then enables considering the difference between toxics regarding the nature of human being impact. This method is obviously more accurate than the equivalent threshold previously described.

While the previous method enable proposing an equivalent carbon monoxide source term, it does not consider the different nature of gas toxicity. To achieve a toxic evaluation using a more complete method as the one described in the ISO 13571 [6], the important data is the emission factor, in $\mathrm{mg}$ by $\mathrm{g}$ of burnt materials. Simplifying simulation is possible using a similar equivalent source term with a single gas but, in that method, irritant and asphyxiant should be distinguished. Furthermore, it should be kept in mind that those quantities are not stationary. The example of car 2 is used hereafter to give an illustration of this phenomena, Figure 9. 


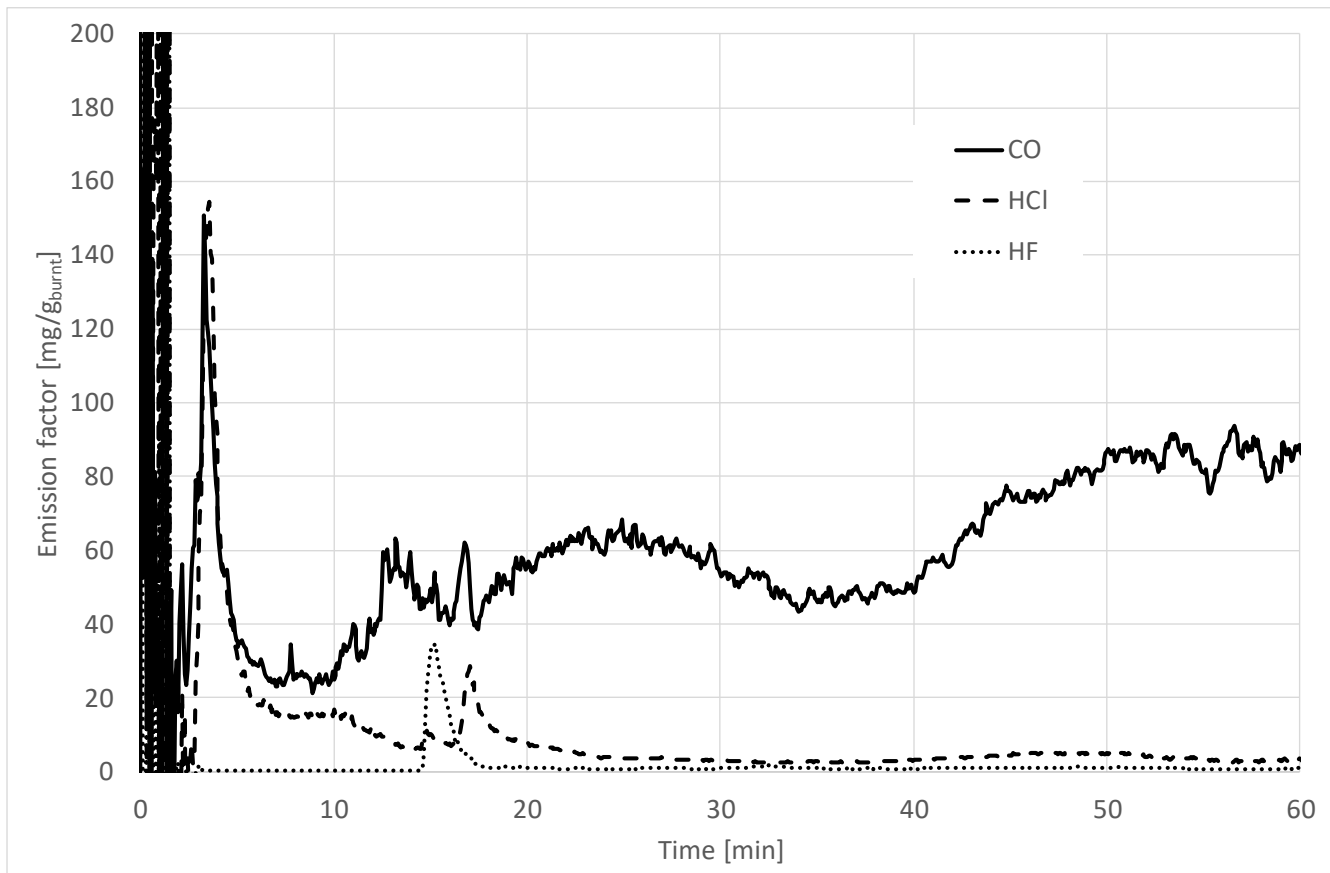

Figure 9 : Evolution of $\mathrm{CO}$ emission factor in $\mathrm{mg}$ of gas $(\mathrm{CO}, \mathrm{HCl}$ and $\mathrm{HF})$ by $\mathrm{g}$ of material burnt.

During the first two minutes, the decorrelation between gas measurements, achieved about $40 \mathrm{~m}$ downstream the fire, and the mass loss rate measurement leads to non-relevant values. Curve should then be considered only after about two minutes. This curve typically shows that, between 2 and 5 min after ignition, the emission of hydrogen chloride could be in the same range than the production rate of carbon monoxide. An emission peak is observed for both $\mathrm{HF}$ and $\mathrm{HCl}$ between 15 and $18 \mathrm{~min}$, it is clear that the sequence of those peaks is crucial for global toxicity as this will be shown on FEC curve. Then, after about $20 \mathrm{~min}$, the production of hydrogen chloride can be neglected. It then appears clearly that using a FED/FEC approach for such fire required having a detailed modelling of species, including source term and transport. Using the experimental data, the FED and FEC curves can be built considering an individu being exposed to the smoke downstream of the fire. Figure 10 shows the $\mathrm{X}_{\mathrm{FED}}$ and $\mathrm{X}_{\mathrm{FEC}}$ evolution during car 2 and car 4 fire tests.

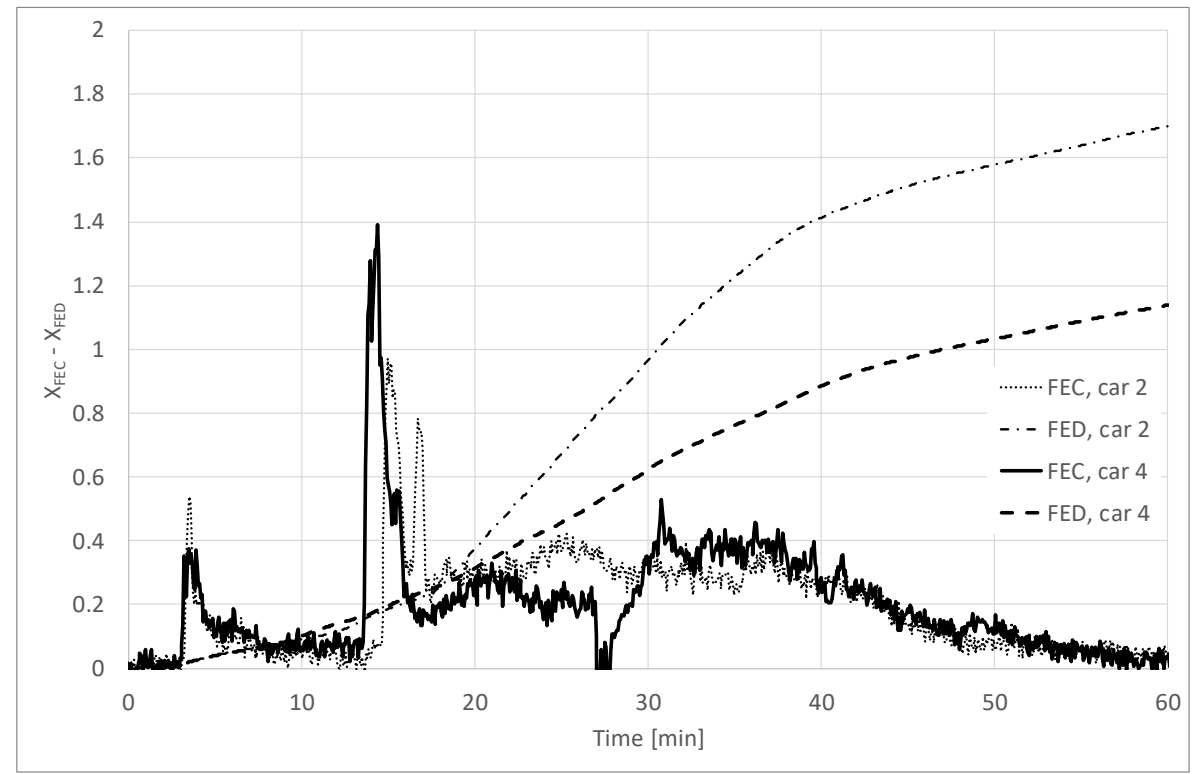

Figure 10 : Evolution of $\mathrm{X}_{\mathrm{FED}}$ and $\mathrm{X}_{\mathrm{FEC}}$ for car 2 and car 4 fire test.

This curve clearly reflects the emission peak of species with a cumulative effect for $\mathrm{HF}$ and $\mathrm{HCl}$ peaks 
that occur after about $15 \mathrm{~min}$. For both vehicles, electric car and equivalent ICE car, this emission peak leads, in the ventilation conditions of the test, to a FEC of 1 that correspond to the loss of evacuation capability for half of exposed persons. The difference of the peak value for FEC is clearly depending of the above discussed sequence of peaks. If the maximum of emissions occurred for both gases exactly at the same time, the consequences are increased while a small-time difference leads to lower consequences. Because of the source for those two gases are different, this sequence clearly depends on the ignition phenomena and fire growth. It must also be highlighted that, the FEC is higher than 1 during a short period. The FED becomes higher than 1 for both cases, after 30 min for the ICE car, after 45 min for electric one.

\section{CONCLUSIONS}

While lots of data are available in the literature regarding the HRR curves for different cars, few existing tests dealt with with toxic gases emission factor. On top of that, most of existing tests were managed in the 90's and an update is interesting to take account cars improvement. Considering that toxicity could be one of the key issues for tunnel fire safety regarding ventilation design, this paper presents fire curves and toxic gases emission factors for recent cars in different categories.

The first important result that appears from those tests is that, while both the total mass of car and plastic fraction were increasing during the last decades, HRR peak values and the total amount of energy released are not so different between published data and those obtained here. It must however be highlighted that standard curves commonly consider a fast fire growth in the very beginning, such a quick growth was not observed during the different tests presented in this paper. This hypothesis of quick fire growth for standard curves is clearly in favor of safety since it imposes a safety system design efficient from the beginning of the event.

Toxic gas measurements show that numerous toxic species are generated during fire and mainly acid gases. While the total amount of those products is not so important, their low toxic thresholds impose to consider them for the toxic impact evaluation. Fire tests also show the importance of dynamic regarding toxic gas emission. One other important result is that electric cars do not lead to a major increase of toxic gases emission factor. Only the total amount of HF rises but the battery contribution occurs after about $30 \mathrm{~min}$, i.e. after the people evacuation.

Finally, based on measurements and existing methods, an equivalent $\mathrm{CO}$ emission factor was built and compared to existing values. This comparison shows that the $\mathrm{CO}$ equivalent production rate could, in such a case, be higher than the commonly used curve, with an increase up to a factor 2 compared with the French commonly used emission factor. Consequently, standard emission factor should be updated regarding those recent results.

Furthermore, when toxicity is the design factor for a ventilation system design, as for ventilation strategies based on stratification, one must consider a more detailed approach based on a realistic source term instead of standard values. For such a situation, modelling several gases should be considered with a FED/FEC approach. One of the main difficulties is then to use a realistic source term for those gases considering that the emission sequence is a key issue as demonstrated in this paper.

\section{REFERENCES}

[1] Ingason, H., "Design fires in tunnels", Safe \& Reliable Tunnels. Innovative European Achievements, Second International Symposium, Lausanne (2006).

[2] Lonnermark, A., Blomqvist, P.; "Emissions from an automobile fire", Chemosphere 62(7) (2006).

[3] Lecocq, A., et al, "Comparisons of fire consequences of an electrical vehicle and an internal combustion engine vehicle", Second International Conference on Fire in Vehicles, September 27-28, 2012, Chicago, USA..

[4] CETU publication, "Guide to road tunnel safety documentation, booklet 4, Specific hazard investigations", (2003).

[5] INERIS $\Omega 16$ document, «Toxicité et dispersion des fumées d'incendie Phénoménologie et modélisation des effets » (2005). 
[6] ISO document 13571, "Life-threatening components of fire - Guidelines for the estimation of time available for escape using fire data" (2012).

[7] SFPE Handbook of Fire Protection Engineering, Fifth edition (2016).

[8] Lam, C., MacNeil, D., Kroeker, R., Lougheed, G. and Lalime, G., "Full-Scale Fire Testing of Electric and Internal Combustion Engine Vehicles", Fourth International Conference on Fire in Vehicles, October 5-6, 2016, Baltimore, USA.

[9] Studiengesellschaft Stahlanwendung E.V. : "EUREKA-Project EU 499 Firetun: Fires in transport tunnels; Report on full-scale tests", Verlag und Vertriebsgesellschaft, Düsseldorf, November 1995

[10] Watanabe, N. et al., "Comparison of fire behaviors of an electric-battery-powered vehicle and gasoline-powered vehicle in a real scale fire test", Second International Conference on Fire in Vehicles, September 27-28, 2012, Chicago, USA.

[11] PIARC Committee on road tunnels, "Systems and equipments for fire and smoke control in road tunnels" (2007).

[12] Persson, B. and Simonson M., "Fire emissions into the atmosphere". Fire Technol. 34 (1998)

[13] Ryan J.V. and Lutes C.C., "Characterization of emissions from the simulated open burning of non-metallic automobile shredder residue", EPA-600/R-93-044, NTIS PB930172914; (1993).

[14] Lemieux P.M. and Ryan J.V., "Characterization of air pollutants emitted from a simulated scrap tire fire", Air Waste Management Association Journal 438 (1993).

[15] Lemieux P.M. and Lutes C.C., D.A. Santoianni, "Emissions of organic air toxics from open burning : a comprehensive review", Energy and combustion Science 30 (2004).

[16] Collet, S., « Amelioration de la connaissance des emissions atmospheriques liees aux brulages de vehicules contribution de cette source a l'inventaire national d'emission - Synthèse », (2013).

[17] Numerical analysis of smoke layer stability, Benjamin TRUCHOT, Mélanie BOEHM et Frederic WAYMEL. ISAVT, BHRG New-York (2009).

[18] Truchot, B. in Fire Safety Sciences News n³8 (2015).

[19] Boehm M., Fournier L. et Truchot B., "Smoke stratification stability: Presentation of experiments", Gratz (2008).

[20] PIARC Committee on road tunnels, « Fire and smoke control in road tunnels (1999).

[21] A. Tewarson, «Generation of heat and fire products », Factory Mutual Research Technical report, (1995). 